\title{
8
}

\section{PRINSIP-PRINSIP BAHASA RUPA}

\section{Primadi Tabrani}

\begin{abstract}
The concept of Fine Language is the result of the creation of a long research, originally in the form of a research report on the science of Fine Language which later developed into dissertation research as much and as thick as 'one coffin' $(58 \times 33 \times 37 \mathrm{~cm})$. This Fine Language is a way of 'reading' pictures, from various images, pictures of children, prehistoric cave pictures, wayang beber pictures, then to symbolic images, decorative images and shadow images from shadow puppets (wayang kulit). Also included are temple relief images and modern drawings, animated images, films and pictures produced by other digital technologies, such as ad images. The word language is different from the image language. In the image language, we can already describe the shape of the drawn. In the word language, use the word to represent an object that is drawn. Often experience miscommunication because with various words (from different regions/tribes/countries) to describe an object. In the language of the image there are wimbas, in the wimba there is the content of wimba and way of wimba. The content of the wimba is a picture contained in the wimba, and the way the wimba is how the wimba is drawn and can be told. Through the 'science' is the original image that is beginning to be understood and retold as teaching materials or materials of scientific art for future studies, about the image of traditions and modern drawings.
\end{abstract}

Keywords: visual language, image, vocabulary, wimba

\section{PENDAHULUAN}

"Ilmu" Bahasa Rupa lahir di Indonesia (1991) di Fakultas Seni Rupa dan Desain (FSRD) Institut Teknologi Bandung (ITB), dalam disertasi Primadi Tabrani, yang merupakan hasil studi perbandingan berbagai bahasa rupa: gambar anak, gambar gua prasejarah, gambar primitip, gambar Wayang Beber Jaka Kembang Kuning, relief cerita Lalitavistara candi Borobudur dan seni rupa modern.

Disertasi ini tebalnya 'satu peti' (58x33x27 cm). Masih ditahun 1991 American Library of Congress_dari Amerika Serikat memesan 7 peti yang di bagikan pada berbagai perguruan tinggi seni rupa di Amerika. Mereka berpendapat bahwa apa yang ditemukan disertasi tersebut merupakan sesuatu yang baru dan belum ada dalam literatur barat. Ketika saya katakan, "Kan ini dalam bahasa Indonesia", mereka menjawab "Tak masalah, banyak ahli kita yang mampu menerjemahkannya". Hati saya terkesiap, jangan jangan temuan disertasi tersebut akan segera disosialisasikan, dan dipraktekkan di Amerika, sedang di Indonesia sendiri belum bergema.

\section{Khasiat Bahasa Rupa}

Apa sebab American Library of Conggres tertarik? Karena Bahasa Rupa ada Khasiatnya.

Dengan 'ilmu' Bahasa rupa kita kini bisa 'membaca' gambar gua Prasejarah, gambar Primitip, gambar tradisi, relief Candi, gambar Anak, Komik, Desain, dsbnya walaupun tak ada teks yang mendampinginya. Gambar Gua 
Prasejarah, Primitip. Relief candi, gambar Anak memang umumnya tanpa teks, bahkan gambar prasejarah tak ada sumber acuannya, karena manusianya telah punah, dan belum ada tulisan . .

Bukan hanya itu, Bahasa Rupa juga bisa membantu kita dalam membuat gambar, membuat segala sesuatu yang kasat mata ....

Membaca gambar dan Membuat gambar bisa dilaksanakan secara manual dan digital. Faktor digital ini jadi menarik. Ilmu Bahasa Rupa lahir dan berkembang seiring dengan munculnya Teknologi Informasi dengan Digital editingnya. Kedua ilmu ini: Bahasa Rupa dan IT (Teknologi Informasi) seakan ilmu 'kembar' yang saling mengisi dan dibutuhkan jamannya...............

Perkembangan IT (Teknologi Informasi) dengan seni digitalnya (Gambar, Foto, Film. Multi media, dan sebagainya) melengkapi senirupa dengan sejumlah 'trik' teknik, semula manual, lalu analog, kemudian digital.

Digital merupakan "teknik" penggambarannya, yang penting bukan hanya kecanggihan teknik digitalnya, tapi hasilnya yang berupa karya yang kasat mata, yang keindahannya membutuhkan estetika, namun keterbacaannya membutuhkan Bahasa Rupa, karena Senirupa adalah sebentuk komunikasi.

\section{Bahasa Rupa dalam Kurikulum}

Karena khawatir temuan temuan disertasi akan segera dimanfaatkan dan dipraktekkan untuk berkarya senirupa di Amerika, team kami segera memasukkan ilmu Bahasa Rupa dalam kurikulum di sejumlah Fakultas Senirupa dan Desain di Indonesia. Diberikan teori Bahasa Rupa, yang mencakup kajian lintas sejarah, sejak prasejarah, tradisi, gambar Anak, sampai seni rupa digital masa kini. Ujiannya berupa proyek tugas baik manual maupun digital. Tugas membaca gambar Tradisi dengan bantuan Bahasa rupa (Ujian Tengah Semester). Dan tugas menggambar folklore tradisi, dengan bantuan Bahasa Rupa (Ujian Akhir semester)

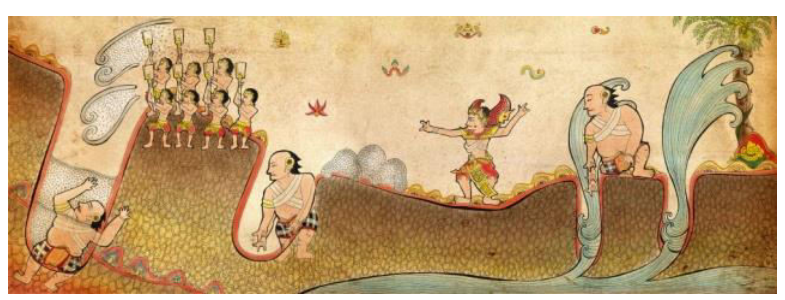

Sumber: data pribadi

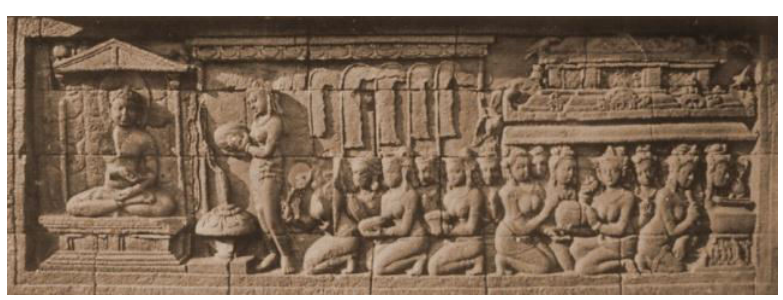

Sumber: data pribadi

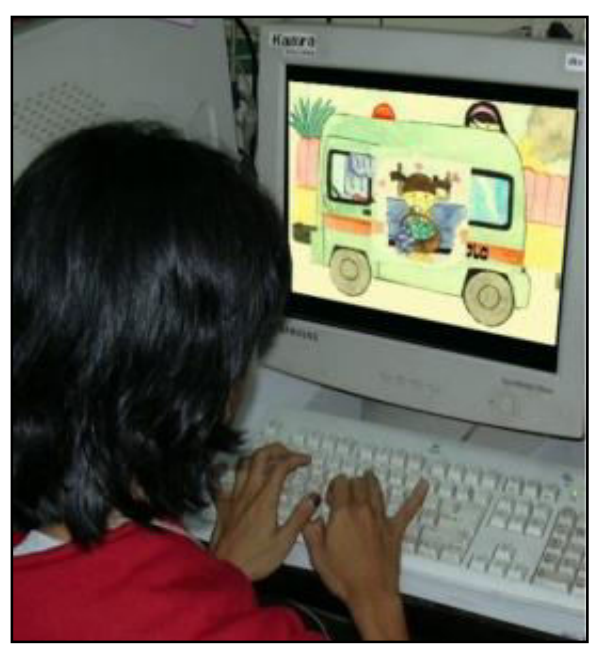

Sumber: data pribadi 


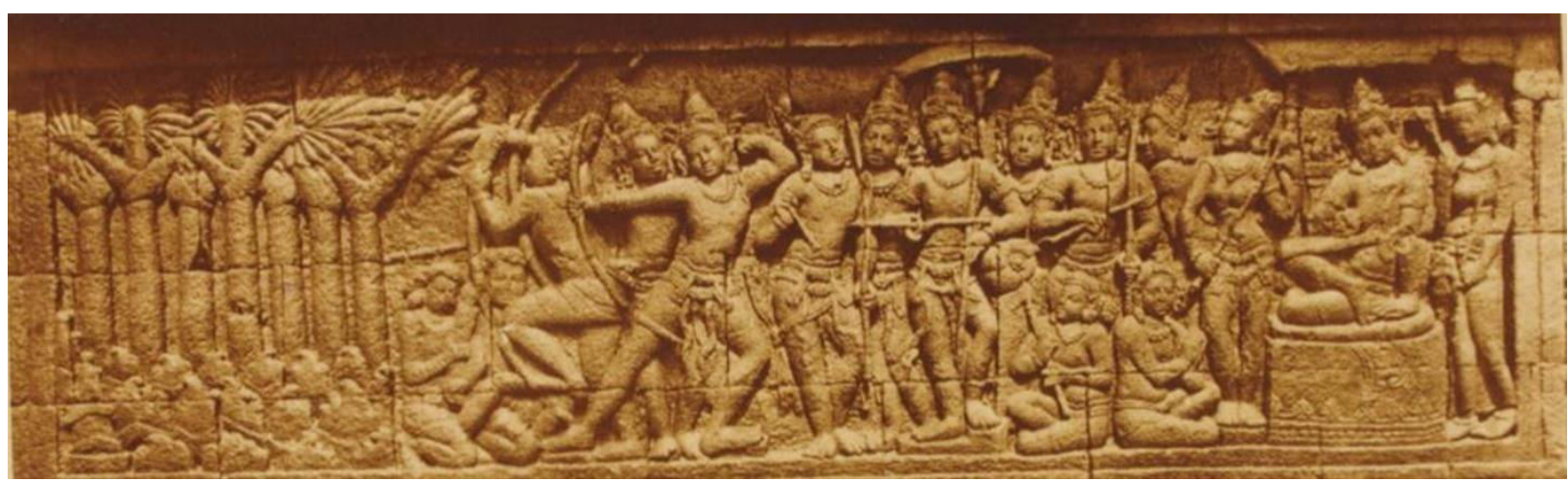

Sumber: data pribadi

\section{Sebuah contoh}

Relief Lalitavistara di Candi Borobudur (800M), dilorong 1, badan candi, deret atas, panil 49 berjudul 'Sayembara Memanah'. Sutranya: 4 paragrap tersebar di 3 halaman. Pada panil nomor 49 ini, sutranya (sastranya) menyebut kisah ini di 4 paragrap yang tersebar di 3 halaman. Pakar Belanda yang mencoba membaca relief ini berdasar sutranya bingung. Paragrap keberapa di halaman mana yang di"abadikan" di panil 49 ini? Pakar Belanda tersebut tidak menemukannya, bahkan ia menduga bahwa para pemahat Borobudur menggunakan teks yang berbeda. Sutra menyebut bahwa Budha mendapat giliran memanah yang terakhir, dan ia memanah sendirian karena semua peserta sayembara memanah lainnya telah meninggalkan lapangan. Tapi mengapa pada relief tampak begitu banyak peserta sayembara lainnya yang seakan baru saja selesai memanah? Budha yang mana? Rasanya yang sedang memanah dilatar depan, sesuai dengan judul panil ini 'Sayembara Memanah'. Tapi di panil ini ada seorang tokoh dilatar depan agak ditengah yang merupakan satu satunya tokoh yang dibawah payung (tokoh terpenting),

ada kemungkinan inilah sang Budha. Akhirnya pakar Belanda tersebut 'menyerah' dan berkata "Mungkin saja para pemahat Borobudur memahat Budha lebih dari satu". Bila kita baca dengan 'ilmu' Bahasa Rupa: Relief ini dibaca dari kanan kekiri (cara Pradaksina). Latar Belakang diceritakan lebih dulu, baru latar di depannya. Selama latar belakang diceritakan, latar depan 'belum' muncul, latar depan baru muncul setelah latar belakang selesai diceritakan (Cara Lapisan Latar).

Jadi di bacanya sebagai berikut: Alkisah pada suatu hari diselenggarakan sayembara memanah. Sang raja yang punya hajat tampak di pojok kanan (diceritakan lebih dulu) sedang menyaksikan para peserta sayembara sedang memanah (di latar belakang - diceritakan lebih dulu). Setelah para peserta malaksanakan gilirannya, mereka meninggalkan lapangan. Kemudian di 'solve' lah Budha di latar depan ditengah, ia mencoba berbagai busur yang berpatahan karena tenaganya yang begitu kuat. Akhirnya diperoleh busur yang kuat dan Budha di 'insert' ke sebelah kiri (diceritakan belakangan setelah Budha yang ditengah), melaksanakan 
giliran memanah. Tenaganya begitu kuat, hingga anak panahnya (diperbesar agar kelihatan), menembus tujuh pohon lontar. Keseluruhan cerita di latar belakang dan di latar depan di 'dissmix', semua tokoh yang pernah 'masuk' panil tampak dan bisa diceritakan.

Ada sedikitnya lima adegan dalam 'sekuen' ini, kesemua 4 paraprap di 3 halaman tersebut, dilebur jadi satu panil 49 ini: cerita yang begitu panjang durasinya di 'dilebur' dalam satu panil !! Panil 49 merupakan gambar tunggal yang 'bercerita'.

\section{Beberapa contoh lainnya}
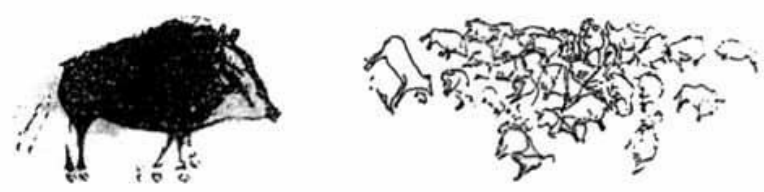

Prasejarah, Altamira, Eropa

Sumber: data pribadi

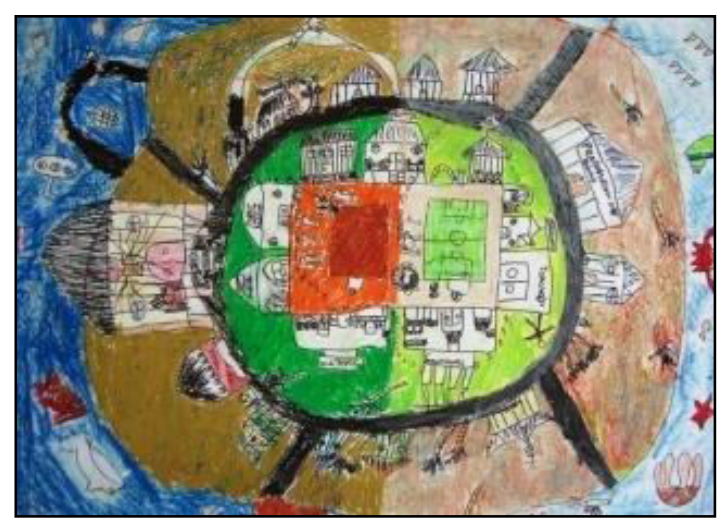

Anak Indonesia, masa kini

Sumber: data pribadi

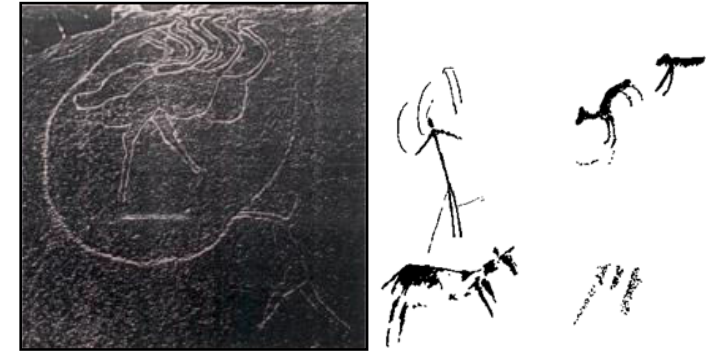

Prasejarah, Afrika

Sumber: data pribadi

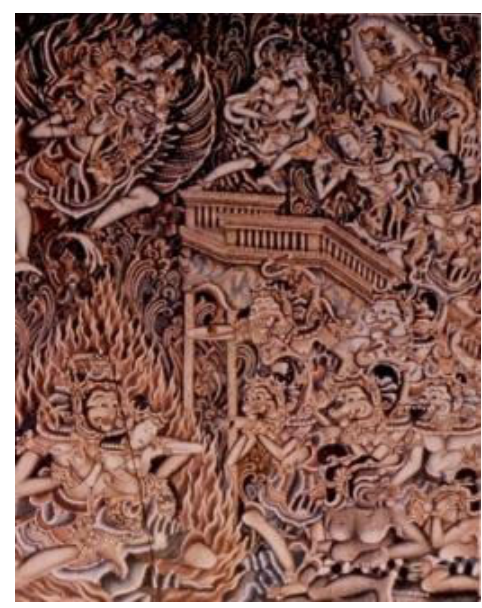

Iklan, masa kini

\section{Kesemua gambar ini merupakan gambar tunggal yang becerita.}

\section{DASAR TEORITIS}

\section{Riwayat Bahasa Rupa}

\section{Awal Mula}

Di tahun 1968 sejumlah mahasiswa senirupa ITB terlibat dalam Jajaran Pendidikan Senirupa yang membina gugus kegiatan senirupa di berbagai tempat di Bandung. Merupakan suatu kejutan bagi kami, karena umumnya para orang tua, dan para guru mendapat kesulitan untuk mengerti gambar anak. Ini dikarenakan anak melihat dan menggambar dengan cara yang berbeda dengan kita manusia dewasa. Kita, 'kaum sekolahan' melihat dan menggambar 
dengan sistem Naturalis-PerspektipMomenopname (NPM) dari Barat yang berglobalisasi melalui kolonialisme. Di Indonesia sejak jaman kolonial, NPM diajarkan di SD sampai saat ini, (gambar gunung dua dengan perspektip jalan, pohon kelapa, tiang listrik dan sebagainya) padahal anak tampaknya menggunakan sistem menggambar yang berbeda.

Itulah sebabnya tim penelitian kami meneliti gambar anak, untuk mencoba 'mengerti' gambar anak, dengan harapan agar kita manusia dewasa (orang tua, para guru) bisa mengapresiasi gambar anak. Yang kami teliti adalah gambar yang representatip - yang mewakili aslinya, (aslinya bisa dikenali) bukan yang abstrak atau geometris.

\subsection{Hasil penelitian: Berbagai Cara Bahasa Rupa}

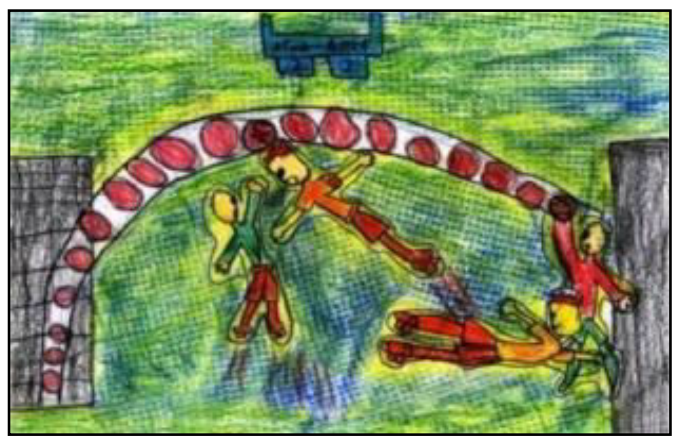

Sumber: data pribadi

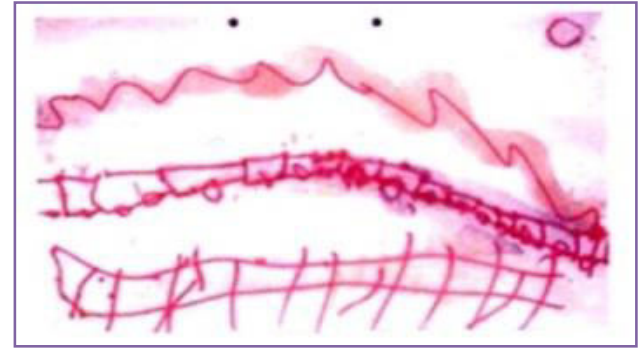

Sumber: data pribadi

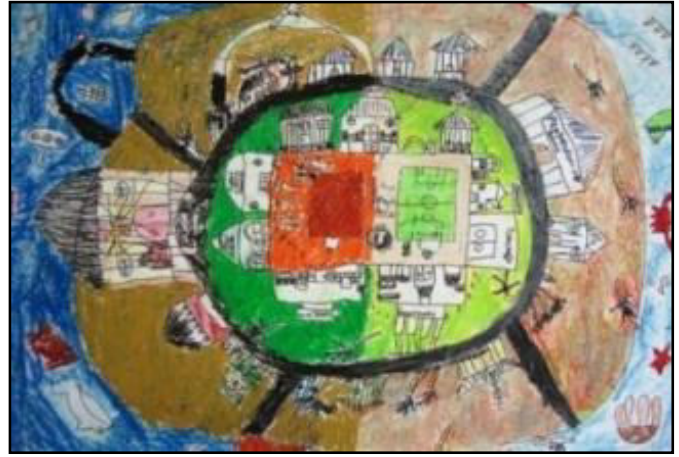

Sumber: data pribadi

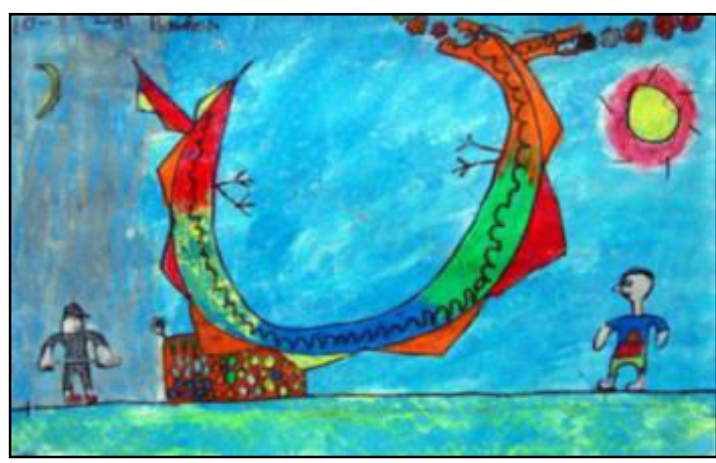

Sumber: data pribadi

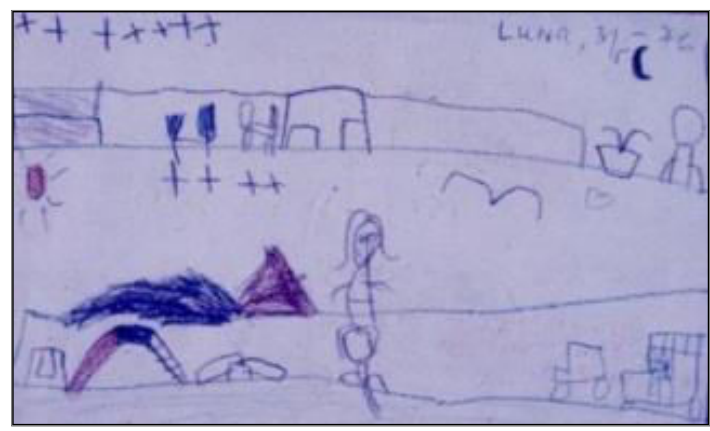

Sumber: data pribadi

- Cara Digeser

- Cara dari kepala - kaki

- Cara Tampak Khas

Semu objek bisa dilihat, dibaca, diceritakan. Sulit disalah tafsirkan

- Cara Media Dingin (Marshall McLuhan) Pemirsa akrip berimajinasi dan berfikir agar mampu 'menangkap' kejadian yang sebenarnya. 
- Tanpa Bingkai (frame), tanpa Perspektip, tanpa Zoom in dan Zoom out,

- Cara Media Dingin (Marshal McLuhan)

\section{Pemirsa aktip berimajinasi dan}

\section{berfikir dan mampu 'menangkap'}

kejadian yang sebenarnya.

- Cara Diperbesar. Cara Diperkecil.

- Tanpa: perspektip/ zoom in-out/

\section{bingkai}

\subsection{Hubungannya dengan MacLuhan, Enstein dan Hawking.}

Pada gambar 'rebahan' favorit anak anak ini, sejumlah bangunan direbahkan keluar jalan lingkar. Bila tegak seperti biasa maka akan ada peristiwa/panorama yang tak kelihatan karena 'terhalangi' hingga tak bisa diceritakan. Karena buat anak gambar = bercerita, maka semua direbahkan keluar, semua tampak, semua bisa dibaca, bisa diceritakan. Hebatnya pemirsa bisa menangkap keadaan/panorama yang sebenarnya!. McLuhan (pakar komunikasi Amerika) menyebut bahwa gambar tunggal Pendahulu (termasuk gambar anak) $=$ media dingin $=$ bahan mentah. Kita para pemirsa yang 'panas' berfikir dan berimajinasi agar dapat menangkap kejadian yang sebenarnya.

Sementara itu McLuhan menyebut gambar NPM barat $=$ media panas: semua sudah lengkap seperti dilihat mata, 'ceklik' seperti dipotret. Pemirsanya jadi 'dingin', tak perlu lagi berimajinasi dan berfikir, terima saja, karena sudah seperti dilihat mata.

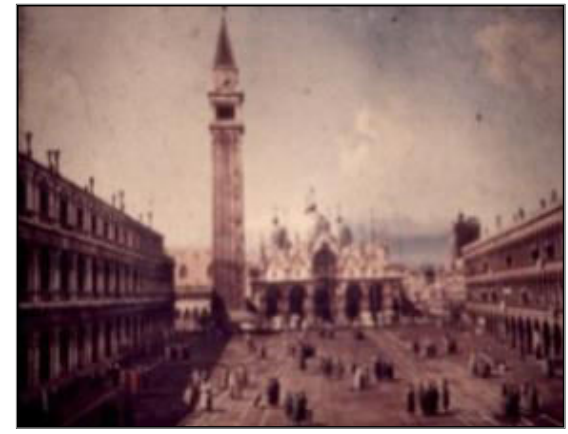

Sumber: data pribadi

Jadi gambar tunggal anak yang 'asli' dan RWD itu memiliki potensi untuk mengembangkan imajinasi dan berfikir...........

Sistem menggambar NPM dari barat didukung fisika Klasiknya Newton (1687), kini sudah 'ketinggalan' lebih dari 325 tahun!! Namun pelajaran menggambar/melukis dan seniman masa kini masih banyak yang ber Newton ria.

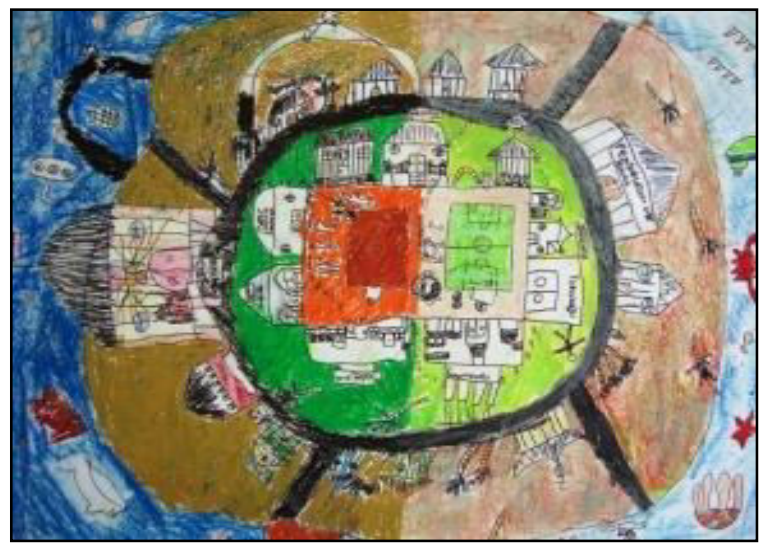

Sumber: data pribadi

Padahal McLuhan telah mengatakan bahwa "Teori Relativitas Khusus Einstein (1906) menyatakan tidak berlakunya lagi ruang Newton (perspektip) yang uniform, berkesinambungan dan rasional, bagaimanapun ia telah bermanfaat dimasa lalu". 
Bagi Newton bidang hanya panjang dan lebar, tanpa dimensi waktu. Benda/ruang hanya panjang, lebar dan tinggi, tanpa dimensi waku. Bagi Einstein bidang $=3$ dimensi: panjang,lebar, waktu. Benda/ruang berdimensi 4: Panjang, lebar, tinggi, waktu.

Hebatnya para seniman 'Pendabulu' (prasejarah, primitip, tradisi, anak) ternyata akrab dengan Teori Relativitas Umum Einstein (1916) dari fisika modern, Teori komunikasi McLuban dan fisika mutakhir Hawking!. Padahal mereka samasekali tak kenal dengan pakar pakar tsb! Sunggub menakjubkan karena sangat mutakhir!!

Bukankah seni seharusnya mencerminkan jamannya?! Dan sekarang bukan lagi

jamannya Newton, tapi jamannya Einstein, McLuban dan Hawking?!

\section{HASIL KAJIAN DAN PEMBAHASAN}

\subsection{Langkah Pamungkas}

Dengan kesemua temuan temuan tersebut, penulis menyelesaikan disertasinya (1991) yang merupakan studi perbandingan antara lukisan prasejarah (60 lukisan, sample dunia), lukisan primitip (30 gambar, sampel dunia), gambar anak (35 gambar, sampel dunia), relief cerita Borobudur (120 panil, media visual tradisi Indonesia, gambar wayang beber (24 gambar, media audio visual tradisi Indonesia). Kesemuanya diperbandingkan dengan seni modern (lukisan, foto, iklan, animasi, dan sebaginya - sample dunia).

\section{Bahasa Kata dan Bahasa Rupa}

Dalam bahasakata, tiap suku dipengaruhi oleh lingkungan dan latar budaya yang berbeda, memiliki istilah yang berbeda untuk menyebut benda yang sama. Misalnya, kuda (Indonesia), horse (Inggris), Uma (Jepang), Cavallo (Itali), Cheval (Perancis), Kabayo (Tagalog), Paard (Belanda), dan sebagainya.

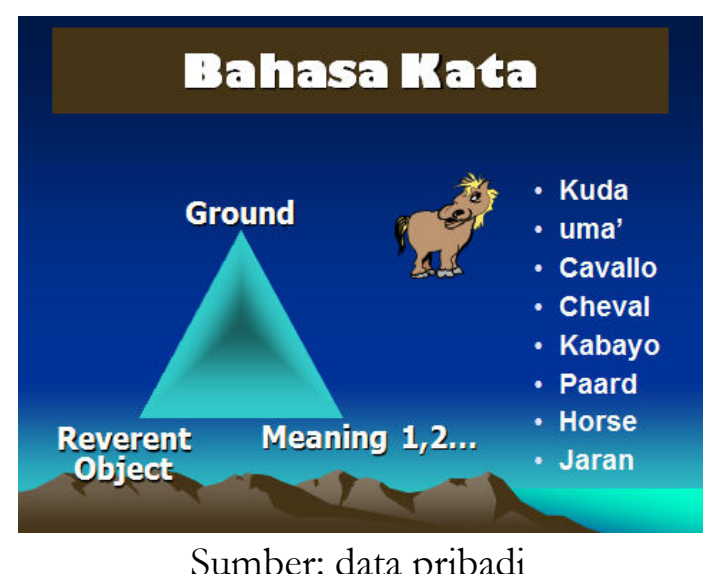

Di bahasa rupa, keadaannya berbeda. Gambar Representatip dari jaman manapun (sejak prasejarah), biasanya bisa dikenali oleh bangsa lain dari jaman manapun. Jadi yang lebih menarik pada bahasa rupa bukanlah gambar apa yang digunakan untuk mewakili suatu objek tertentu (seperti di bahasakata), tapi bagaimana objek itu digambar. Karena bahasarupa merupakan suatu 'ilmu' yang baru, terutama bahasarupa RWD, (belum ada dalam literatur barat) kami memerlukan menciptakan beberapa istilah baru.

Jurnal Budaya Nusantara Vol. 1 No. 2 | 189 


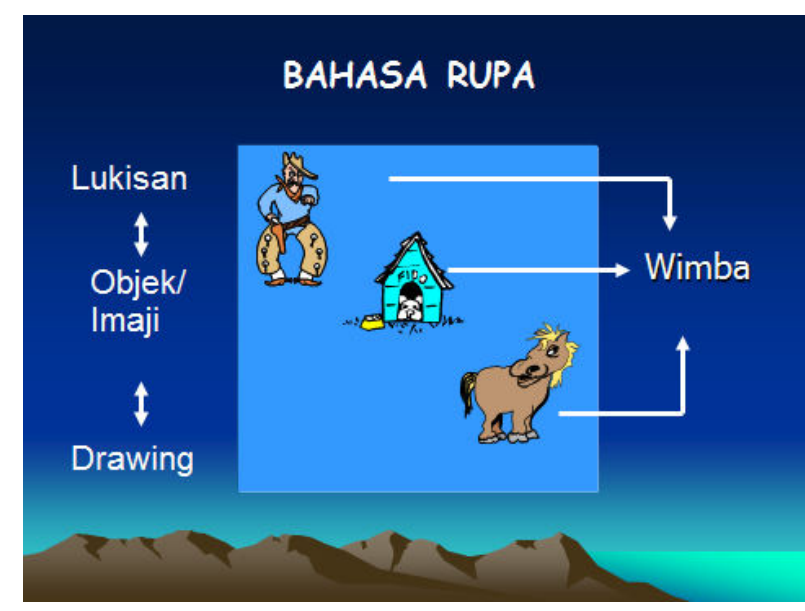

Sumber: data pribadi

Yang pertama adalah Wimba. Kita menyebut gambar didalam gambar yang lebih besar sebagai wimba. Di ilustrasi ini pada gambar yang besar ada tiga wimba: wimba koboy, wimba kandang dan wimba kuda. Ada dua jenis wimba: Isi Wimba, objek apa yang digambar dan Cara Wimba, cara objek digambar. Cara Wimba digunakan untuk satu wimba agar bisa bercerita.

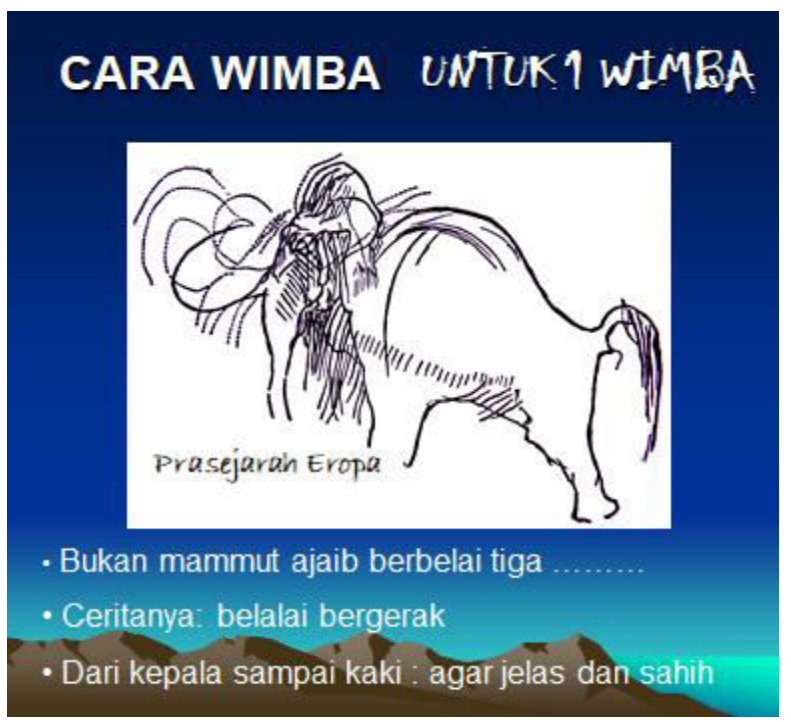

Sumber: data pribadi

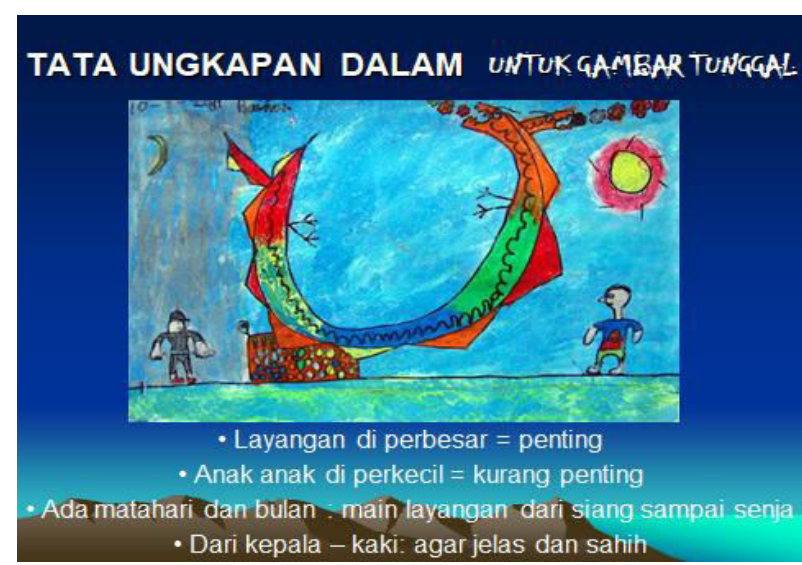

Sumber: data pribadi

\section{Perkembangan Penelitian}

Penelitian Bahasa upa terus dikembangkan. Telah diteliti bahasa rupa wayang golek dan wayang kulit. Sampai 1991 - 1993, penelitian telah menemukan suatu perbendaharaan bahasarupa yang terdiri dari 168 Cara, 120 dari system NPM (beberapa diantaranya juga berlaku untuk sistem RWD), dan 48 dari sistem RWD (yang tidak berlaku untuk sistem NPM). Perbendaharaan ini masih terus berkembang. Sejumlah candi di pulau Jawa telah disingkap bahasa rupanya oleh para mahasiswa yang mengambil S2 dan S3. Begitu pula sejumlah gambar cadas prasejarah di Indonsia.

\section{Cara Wimba dan Tata Ungkapan untuk} gambar Tradisi

\section{Cara Wimba}

CW 1: Ukuran Pengambilan

$$
\begin{aligned}
& \text { 12. Ada yang diperbesar } \\
& \text { 13. ada yang di perkecil } \\
& \text { 14. Dari kepala-kaki }
\end{aligned}
$$

CW 2: Sudut Pengambilan

\section{Sudut wajar \\ $\underline{\text { 3. Sudut atas }}$}


4. Tampak burung
5. Aneka tampak
6. Sinar $X$

CW 3: Skala

1. Lebih kecil dari aslinya

2. Sama dengan aslinya

3. Lebih besar dari aslinya

4. Ukuran Raksasa

CW 4: Cara Penggambaran

3. Stilasi

4. Ekspresif

6. Skematis

7. Dekoratif

$\underline{\text { 8. Blabar }}$

9. Garis

10. Siluet

12. Warna

13. Bidang

15. Kejadian

16. Aneka tampak

17. Perwakilan

CW 5: Cara Dilihat

1. Sudut lihat atas

2. Sudut lihat wajar

3. Sudut lihat bawah

7. Arah lihat wajar

10. Arah libat pradaksina/prasavya

11. Arah libat bawah atas

12. Arah lihat tengah pinggir

13. Arah lihat pinggir tengah

14 Arah libat berhadapan

15. Arah libat berkejaran

16. Arah libat rata-rata

17. Arah libat berkeliling

18. Arah libat darimana saja
Catatan:

$\underline{\text { Huruf tegak bergaris }}=\mathrm{NPM}+\mathrm{RWD}$

Huruf miring = hanya RWD

\section{Tata Ungkapan Dalam}

TUD 1: Menyatakan ruang

3. Naturalisasi

5. Relief \& barik

7. Tanpa Garis Tanah

8. Garis Tanah

9. Sejumlah latar

10. Digeser

11. Ruang Angkeasa

12. Rebahan

13. Identifikasi Ruang

TUD 2: Menyatakan gerak

4. Garis-garis ekspresif

5. Garis-garis tambahan

6. Bentuk dinamis

7. Imaji jamak

8. Ciri gerak

TUD 3: Menyatakan waktu \& ruang

3. Imaji jamak

4. Campuran

5. Dismix

6. Aneka ruanga \& waktu (dream time)

7. Kembar

8. Ciri waktu \& ruang

9. Lapisan latar

10. Urutan di suatu latar

11. Garis tanah jamak

12. Kronologis di suatu gambar

13. Kilas balik

14. Kilas maju 
TUD 4: Menyatakan penting

$\underline{5 . ~ S k a l a ~ g a b u n g a n ~}$

6. Di tengah

7. Di Kiri/Atas

$\underline{\text { 8. Frekuensi penampilan }}$

9. Diperbesar

10. Rinci diperbesar

11. tampak khas

12. Sinar $X$

13. Di kanan/bawah

Catatan:

$\underline{\text { Huruf tegak bergaris }}=\mathrm{NPM}+\mathrm{RWD}$

Huruf miring = hanya RWD

\section{PENUTUP DAN KESIMPULAN}

Demikianlah Prinsip prinsip Bahasa Rupa, sebagai pengantar Lokakarya "Membaca Relief Borobudur" ini. Dalam Lokakarya ini kita akan belajar "membaca" relief berdasar gambarnya, selangkah demi selangkah dan semoga setelah lokakarya ini kita semua memiliki kemampuan untuk membaca relief.

Sekian, Terimakasih, selamat berloka karya. Semoga berhasil.

\section{DAFTAR PUSTAKA}

De Graaf, 1986, Puncak Kekuasaan Mataram, terjemahan Pustaka Grafiti Press dan KITLV, PT Pustaka Grafitipres, Jakarta

Ekspedisi Cincin Api, 2011., “Toba Mengubah Dunia”, Kompas 15.10.2011: 38
Hekeren, HR van,

1972, The Stone Age of Indonesia, Koninkelijke Institut voor Taal, Land en Volkenkunde, The Hague.

King, M, Elizabeth, (?), Possible Indonesian or South East Asian influniversity of Pensilvaniya, Philadelphia, USA.

Kosasih, SA,

1982, "Tradisi Berburu pada Lukisan Gua di pulau Muna, Sulawesi Tenggara, Laporan Rapat Evaluasi Hasil Penelitian Arkeologi - 1, Pusat Penelitian Arkeologi Nasional, Jakarta.

Krom, N.J.,

1927, Barabudur - Archaeological Description, Martinus Nijhoff, The Hague.

Meulen, S.J. van der,

1988, Indonesia diambang Sejarah, Penerbit Kanisius, Yogya.

Morwood, Mike,

2002, Vision from the Past, Smithsonian Instution Press.

Pindi Setiawan,

2010, Gambar Cadas Kutei Prasejarah: Kajian Pemenuhan Kebutuhan terpadu dan Komunikasi Rupa, Disertasi Doktor, FSRD - Institut Teknologi Bandung.Primadi Tabrani, 2011 (1999, 
1995), Belajar dari Sejarah dan Lingkungan,

Penerbit ITB, Bandung

Primadi,

1991, Meninjau Bahasarupa Wayang Beber Jaka Kembang Kuning dari telaah Cara Wimba dan Tata Ungkapan Bahasarupa media ruparungu dwimatra statis modern, dalam hubungannya dengan Bahasarupa gambar Prasejarah, Primitip, Anak, dan relief Lalitavistara Borobudur, Disertasi Doktor, Fakultas Pasca Sarjana ITB.

"Kapal Cadik Borobudur" Jurnal Dimensi, FSRD Trisakti, vol2-no.1, September 2004.

2011 (1995, 1999), Belajar dari Sejarah dan Lingkungan, Penerbit ITB, Bandung.

Read, Robert Dick, 2008, Penjelajah Bahari, Pengaruh Peradaban Nusantara di Afrika, Penerbit Mizan, Bandung.

Retno Bintarti, "Sebelum lewat Tanjung Harapan, hati masih ciut", Kompas, 8-32001: 48.

Soedjoko,

1981, Ancient Indonesian Technology, Shipbuilding and Arms Production around the XVI century, Aspects of Indonesian Archeology, Pusat Penelitian Arkeologi Nasional. 


\section{KETENTUAN PENULISAN ARTIKEL \\ JURNAL BUDAYA NUSANTARA}

1. KETENTUAN UMUM: Artikel yang dikirim adalah hasil karya sendiri dan belum pernah dipublikasikan. Bahasa yang digunakan berupa bahasa Indonesia atau bahasa Inggris.

2. FORMAT: ukuran kertas A4, huruf Garamond, ukuran huruf 12 pt, margin: kiri 2,5 cm, kanan $2 \mathrm{~cm}$, atas 2,5 cm, dan bawah $2 \mathrm{~cm}$. Khusus abstrak, ukuran huruf $10 \mathrm{pt}$. Ketentuan jumlah halaman: 10-20 halaman (termasuk abstrak).

3. SISTEMATIKA PENULISAN: Judul, nama penulis (tanpa gelar), abstrak, asal perguruan tinggi, pendahuluan, metode kajian, hasil analisis, pembahasan, kesimpulan, dan daftar pustaka.

4. JUDUL: ditulis dengan huruf kecil, kecuali huruf awal kata ditulis kecil (tidak termasuk kata tugas: preposisi dan konjungsi) dan jumlah kata tidak boleh lebih dari 15 kata (tidak termasuk kata tugas).

5. NAMA PENULIS: nama ditulis lengkap, tanpa disertai gelar dan ditulis dengan huruf kapital pada setiap huruf awal kata, sedang lainnya berupa huruf kecil.

6. ASAL PERGURUAN: ditulis dengan huruf kapital untuk setiap huruf awal kata dan lainnya dengan huruf kecil.

7. ABSTRAK: berisi tujuan, metode kajian, hasil kajian, kata kunci. Jumlah kata antara 80-150 kata. Jarak antarbaris 1 spasi.

8. PENDAHULUAN: berisi latar belakang, tujuan, asumsi, manfaat, tinjauan pembahasan yang sudah ada, dan metode kajian.

9. DASAR TEORITIS: teori-teori yang mendasari pembahasan dan kerangkah teoritis.

10. HASIL KAJIAN DAN PEMBAHASAN: berisi temuan-temuan empirik dan pembahasan terhadap kebenaran temuan-temuan yang dikaitkan dengan konsep-konsep dan teori-teori terkait.

11. PENUTUP: berisi kesimpulan dan saran atau rekomendasi, berikut diskusi

KESIMPULAN: bila tulisan merupakan suatu hasil penelitian/tesis/disertasi.

REKOMENDASI: bila tulisan mengharapkan aksi-aksi tertentu; bila diperlukan, dapat membuat sub-bab. 
DISKUSI: bila permasalahan dianggap perlu untuk membuka wacana, sehingga para pembaca/publik dapat memberikan pendapat/ masukan/ kritikan tentang wacana yang dibahas.

Pendapat dan kritikan pembaca, serta sanggahan penulis akan diterbitkan pada jurnal terbitan berikutnya.

12. DAFTAR PUSTAKA: menggunakan tata aturan standar atau EYD. Contoh:

Pawlak, Mirosław dan Larissa Aronin. 2014. Essential Topics in Applied Linguistics and Multilingualism. New York: Springer.

13. CATATAN PUSTAKA: ditulis dengan urutan nama akhir penulis, tahun terbit, dan halaman (bisa tanpa halaman bila merujuk ke buku sumber dan tidak pada halaman tertentu). Contoh: Mirosław dan Aronin (New York: 2014) atau (Mirosław dan Aronin, New York: 2014).

14. PENGIRIMAN NASKAH: bisa diemailkan ke lpik.unipasby@gmail.com atau dikirim langsung ke redaksi Jurnal Budaya Nusantara, Unit LPIK Pusat Budaya Nusantara (Jl. Ngagel Dadi III-B No. 37 Surabaya 60245; Telp./Fax. 031-5053468) dalam bentuk naskah ketikan dan soft copy dalam CD.

15. HAK PENYUNTING: berhak melakukan pengeditan. 